\title{
Fluorous mixture synthesis (FMS) of enantiomers, diastereomers, and compound libraries
}

\author{
Wei Zhang \\ Fluorous Technologies, Inc. University of Pittsburgh Applied Research Center, \\ 970 William Pitt Way Pittsburgh, PA 15238, USA \\ E-mail: w.zhang@fluorous.com
}

(received 23 Mar 04; accepted 21 May 04; published on the web 28 May 04)

\begin{abstract}
Fluorous mixture synthesis (FMS) is a newly developed highly-efficient solution-phase technology. A set of substrates attached to homologous fluorous tags is mixed and taken through a sequence of organic reactions. The final mixtures are demixed by fluorous HPLC and detagged to give individually pure final products. Applications of FMS for the preparation of two enantiomers of pyridovericin, 16 diastereomers of murisolin, and a 560-member mappicine library are highlighted in this article.
\end{abstract}

Keywords: Fluorous mixture synthesis, fluorous HPLC, pyridovericin, murisoline, mappicine

\section{Contents}

Introduction

1. Synthesis of enantiomers

2. Synthesis of stereoisomers

3. Synthesis of analogs

4. Synthesis of compound libraries

Conclusions

\section{Introduction}

Traditional solution-phase organic reactions have advantages of favorable reaction kinetics and easy intermediate analysis by TLC, HPLC, and NMR. However, compounds are usually produced "one at a time" followed by a tedious purification process such as chromatography, distillation or crystallization. Recent advances of high-throughput screening technologies have generated a strong demand on production of large number of molecules for biological tests. Many new technologies such as solid-phase synthesis, solution-phase parallel synthesis, and 
high-throughput purification have been developed to speed up the synthetic process. Among them, the "split and pool" mixture synthesis on solid support has high efficiency in preparation of large compound libraries. However, the nature of heterogeneous reaction and difficulty in monitoring the reaction process have limited the growth of solid-phase synthesis. Implementation of mixture synthesis strategy to the solution phase was not successful simply because of the lack of general ways to separate, analyze, and identify reaction intermediates and final products. The recent development in fluorous technologies ${ }^{1}$ made it possible for the first time to prepare individually pure compounds by solution-phase mixture synthesis. Fluorous synthesis successfully combines the favorable characteristics of solution-phase reactions with solid-phase type separations.

In FMS, perfluoroalkyl groups are employed as the "phase tags" attached to the substrates. The tagged molecules are well soluble in common organic solvents. The capability of fluorous HPLC to separate mixtures of fluorous compounds based on their fluorine content provides a powerful tool to analyze reaction intermediates and demix products. ${ }^{2}$ The fluorous HPLC column containing a stationary phase of $\mathrm{Si}(\mathrm{Me})_{2} \mathrm{CH}_{2} \mathrm{CH}_{2} \mathrm{C}_{8} \mathrm{~F}_{17}$ has a strong and selective retention of fluorous compounds. ${ }^{3}$ Molecules with longer fluorine chains (Rf) have longer retention times on the column. A typical mobile phase for fluorous HPLC is a gradient of $\mathrm{MeOH}-\mathrm{H}_{2} \mathrm{O}$ with increasing $\mathrm{MeOH}$ up to $100 \%$, similar to reverse-phase HPLC. Other solvents such as MeCN or THF can be used to replace $\mathrm{MeOH}$ for the gradient elution. Fluorous HPLC separation of a 9-component mixture of isonipecotic acid derivatives containing different tags (Rf) is demonstrated in Figure 1. ${ }^{4}$ Eight fluorous compounds ( $\mathrm{Rf}=\mathrm{C}_{3} \mathrm{~F}_{7}$ to $\mathrm{C}_{10} \mathrm{~F}_{21}$ ) are well separated in $30 \mathrm{~min}$. The non-fluorous compound $\left(\mathrm{Rf}=\mathrm{C}_{7} \mathrm{H}_{15}\right)$ is eluted out with the solvent front simply because of its low affinity for the fluorous stationary phase.

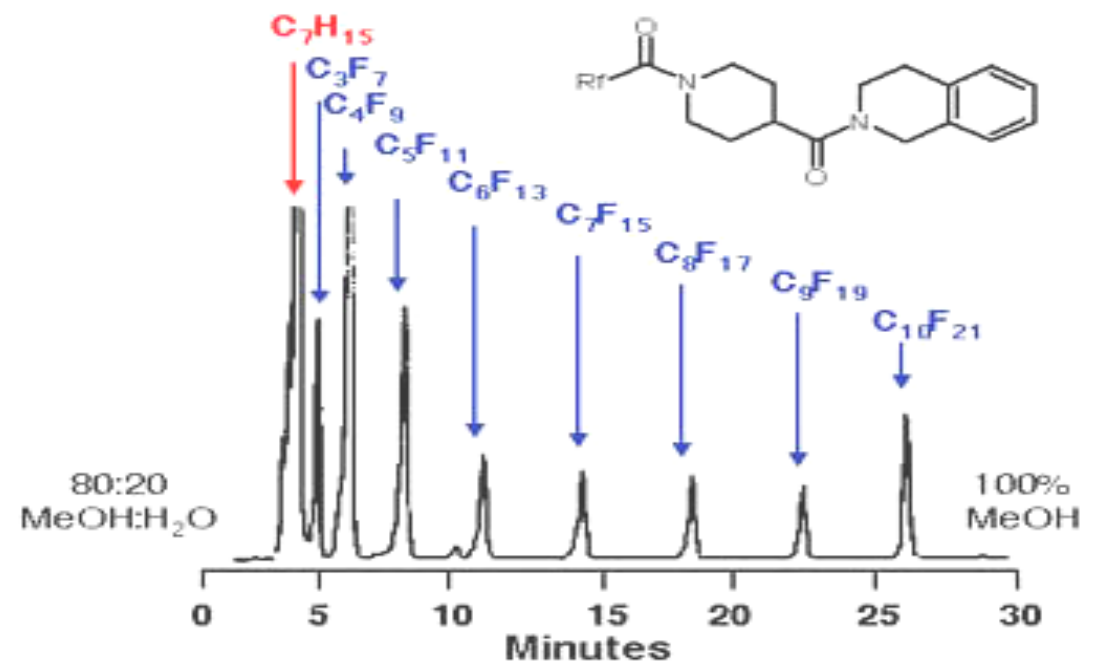

Figure 1. F-HPLC of eight fluorous homologues on FluoroFlash ${ }^{\mathrm{TM}}$ column. 
Scheme 1 illustrates the concept and general procedures involved in FMS: ${ }^{5} 1$ ) attaching of a set of substrates with a corresponding set of homologous fluorous tags with increasing fluorine content; 2) mixing of the tagged substrates together; 3) conducting multi-step mixture synthesis in one-pot or split-parallel fashion; 4) demixing of mixtures of tagged products by fluorous HPLC; and 5) detagging to release final products. The efficiency of FMS is directly proportional to the number of components mixed (step 2), the length of mixture synthesis (step 3), and the number of split (step 3) as well.

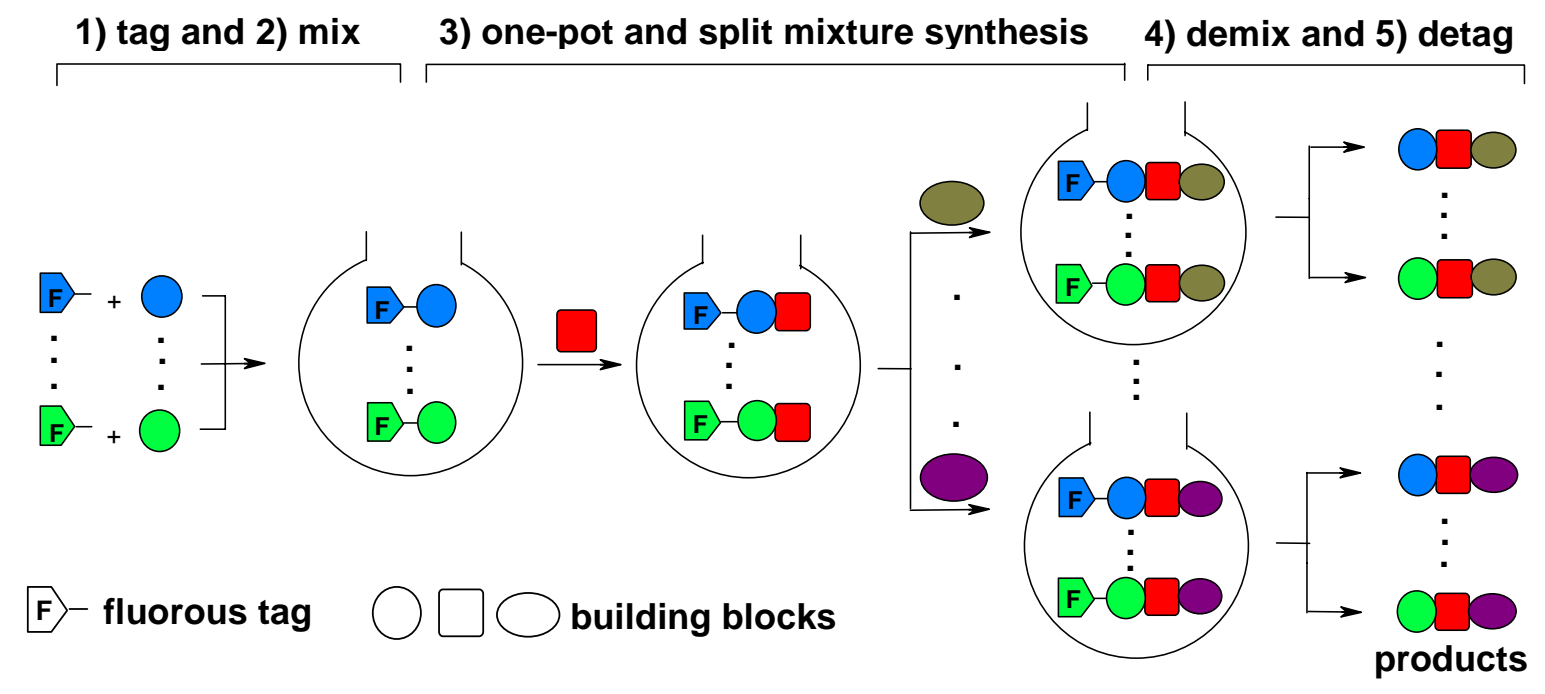

Scheme 1. Schematic diagram of the concept of FMS.

\section{Synthesis of enantiomers}

Enantiopure or enantioenriched compounds are usually prepared by asymmetric synthesis or by resolution of a racemic synthesis. FMS provides an alternative and efficient way to produce enantiomeric products by FMS. The Curran group reported the first example of one-pot synthesis of two enantiomers of pyridovericin (Scheme 2$).{ }^{6}$ The $(S)$ - and $(R)$-enantiomers of the starting material were attached to two different fluorous silanes ( $\mathrm{Rf}=\mathrm{C}_{6} \mathrm{~F}_{13}$ and $\left.\mathrm{C}_{8} \mathrm{~F}_{17}\right)$ and combined together to make a quasienantiomeric mixture. The mixture was then taken through a multi-step synthesis to make a final tagged product mixture. Two quasienantiomers were demixed by fluorous HPLC. The tags were then removed to release the $(S)$ - and $(R)$-enantiomers of pyridovericin. Quasiracemic synthesis is the simplest version of FMS which has only two mixture components. Only one-pot reactions, no split-parallel reactions are conducted in the quasiracemic synthesis. 


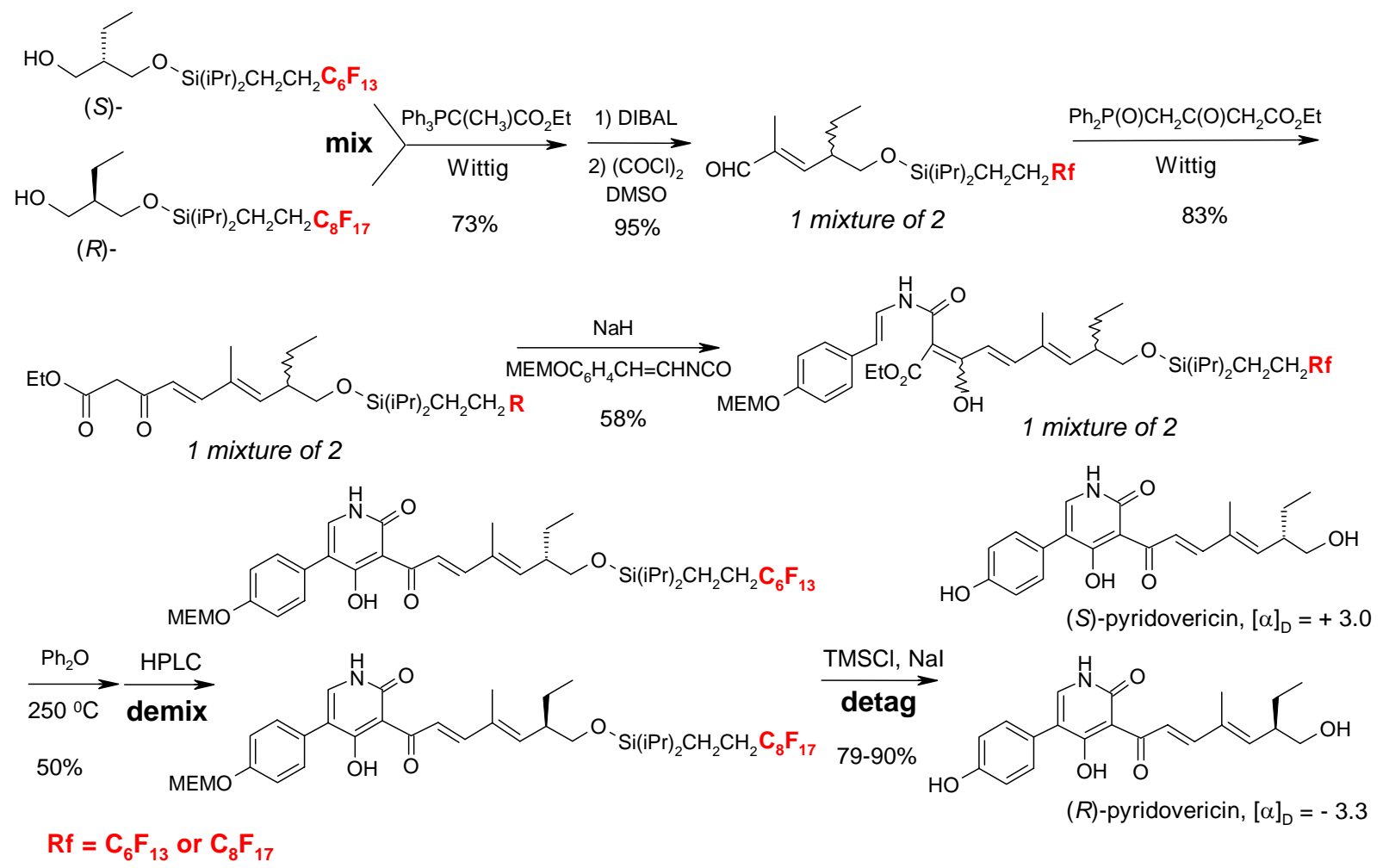

Scheme 2. Quasiracemic FMS of $(S)$ - and $(R)$-pyridovericins.

Enantiomeric amino acid attached to different fluorous Cbz groups provides a useful starting point for the FMS of peptides. ${ }^{7}$ The (D)- and (L)-phenylalanines were tagged with fluorous $\mathrm{Cbz}$ with $\mathrm{C}_{6} \mathrm{~F}_{13}$ and $\mathrm{C}_{8} \mathrm{~F}_{17}$, respectively. The mixture of two quasienantiomers was then coupled with tetrahydroisoquinoline under conventional solution-phase reaction conditions (Scheme 3). The crude product was purified and resolved into its quasienantiomeric components by fluorous HPLC.<smiles></smiles><smiles>O=C(O)NC(Cc1ccccc1)C(=O)O</smiles>

(L)-Phe
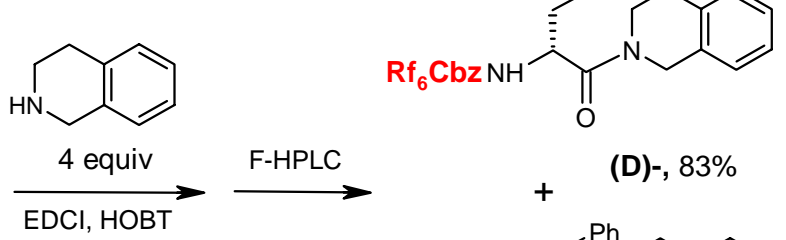<smiles>[R16][R6]NC(Cc1ccccc1)C(=O)N1CCc2ccccc2C1</smiles>

(L)-, 81\%

Scheme 3. FMS of (D)- and (L)-Phe derivatives. 


\section{Synthesis of stereoisomers}

The Curran group recently reported the synthesis of 16 diastereomers of murisolin by FMS. ${ }^{8}$ The murisolin family of acetogenins has 6 stereocenters and this research focused on the synthesis of 16 stereoisomers of the dihydoxy tetrahydofuran fragment (shown in the box) with the $4(R)$ and $34(S)$ centers fixed.

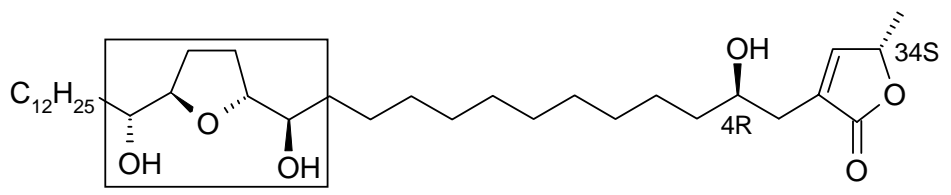

(+)-murisonlin

The FMS started with a mixture of four enantiomerically pure compounds, each tagged with a PMB containing differing Rf group $\left(\mathrm{C}_{2} \mathrm{~F}_{5}, \mathrm{C}_{4} \mathrm{~F}_{9}, \mathrm{C}_{6} \mathrm{~F}_{13}\right.$, and $\left.\mathrm{C}_{8} \mathrm{~F}_{17}\right)$. This mixture was then taken through a sequence of organic reactions, including 2 splits and parallel syntheses to give 4 mixtures of four tagged products (Scheme 4). Fluorous HPLC demix of the 4 mixtures followed by detagging provided 16 desired diastereomers of murisoline. Since FMS has a total of 39 steps, compared to 156 steps that would be required for the same transformations using conventional parallel synthesis, the efficiency advantage is obvious.

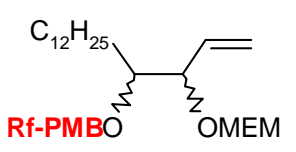

1 mixture of 4

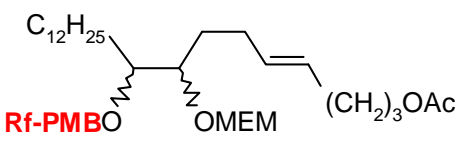

1 mixture of 4

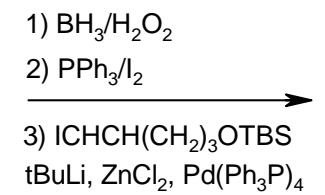

1) 1st split, epoxidation

2) CSA

3) 2nd split, Mitsunobu inversion

4) $\mathrm{NaOH}$

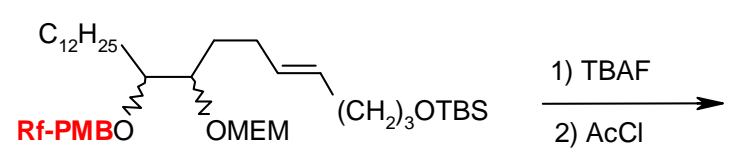

1 mixture of 4
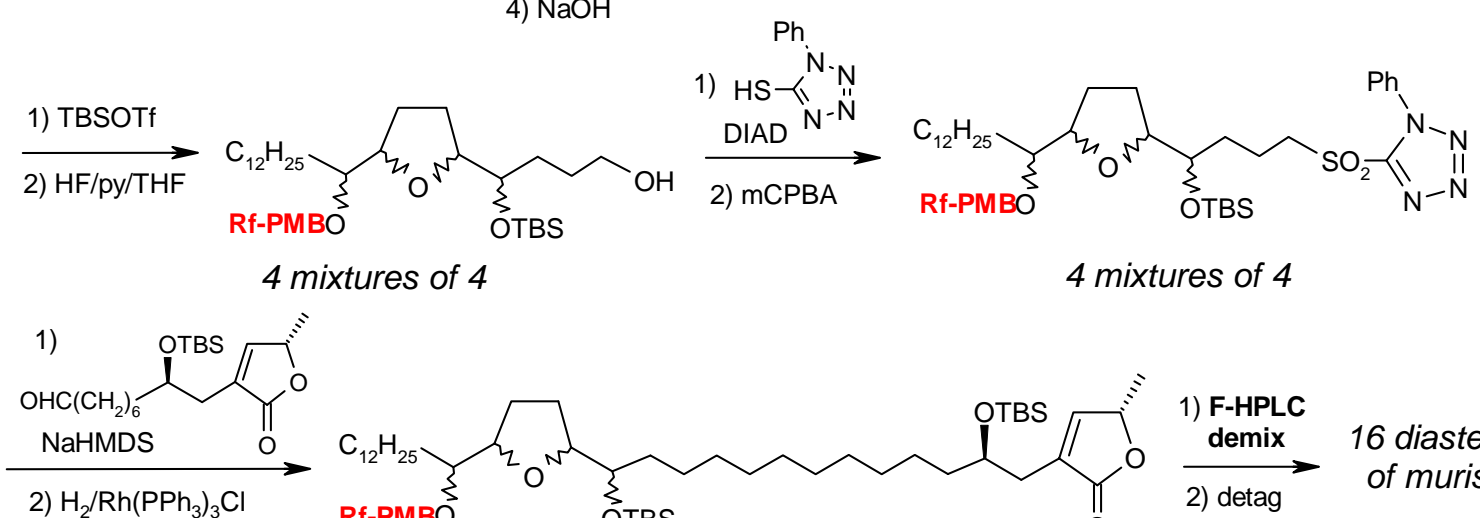

2) $\mathrm{H}_{2} / \mathrm{Rh}\left(\mathrm{PPh}_{3}\right)_{3} \mathrm{Cl}$

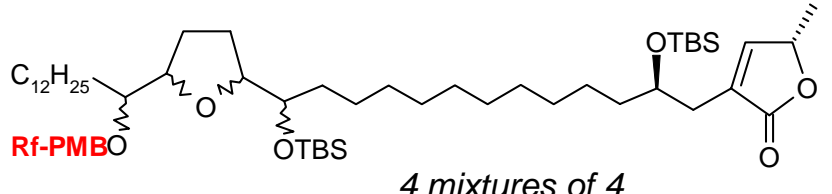

1) F-HPLC demix 16 diastereomers 4 mixtures of 4

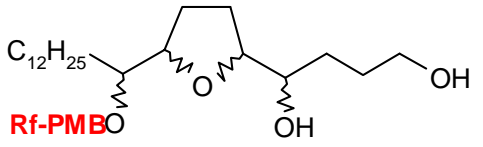

4 mixtures of 4

4 mixtures of 4

Rf-PMB $=\mathrm{Rf}\left(\mathrm{CH}_{2}\right)_{3} \mathrm{O}-\mathrm{Rf}=\mathrm{C}_{2} \mathrm{~F}_{5}, \mathrm{C}_{4} \mathrm{~F}_{9}, \mathrm{C}_{6} \mathrm{~F}_{13}, \mathrm{C}_{8} \mathrm{~F}_{17}$

Scheme 4. FMS of 16 stereoisomers of murisoline. 


\section{Synthesis of analogs}

Synthesis of truncated analogs of the natural product (+)-discodermolide at $\mathrm{C} 22$ position is another successful application of FMS. ${ }^{9}$ Four starting materials with different $\mathrm{R}\left(\mathrm{H}, \mathrm{CH}=\mathrm{CH}_{2}\right.$, $\mathrm{Et}, \mathrm{Ph}$ ) were protected with the corresponding fluorous PMB ( $\mathrm{Rf}=\mathrm{C}_{4} \mathrm{~F}_{9}, \mathrm{C}_{6} \mathrm{~F}_{13}, \mathrm{C}_{8} \mathrm{~F}_{17}, \mathrm{C}_{10} \mathrm{~F}_{21}$ ) (Scheme 4) and mixed. Multistep synthesis of this 4-component mixture led to 4 truncated analogs of discodermolide after demix and detag (Scheme 5).

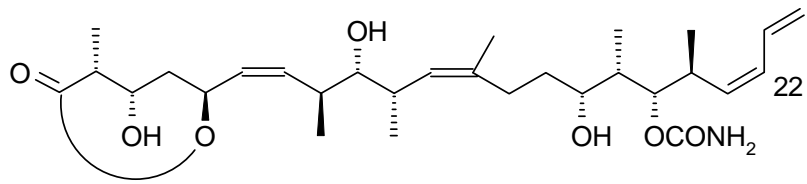

(+)-discodermolide
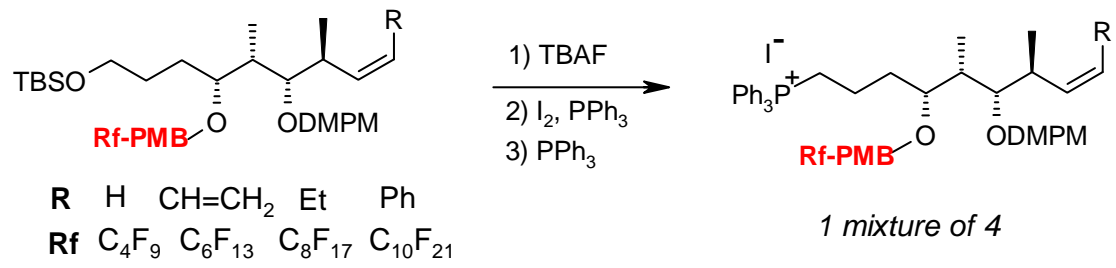

1 mixture of 4

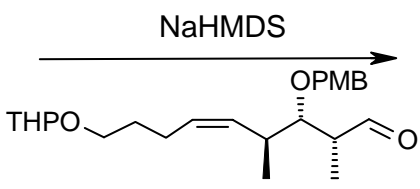

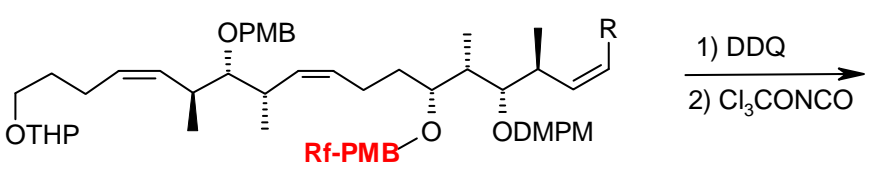

1 mixture of 4

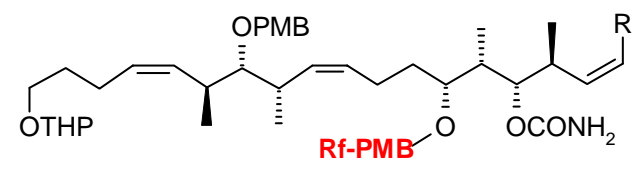

1 mixture of 4

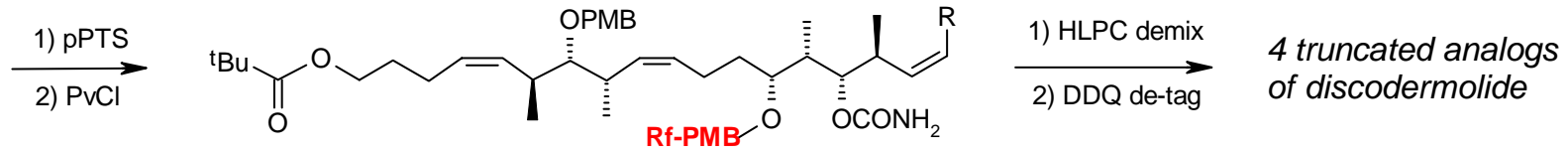

1 mixture of 4

Scheme 5. FMS of 4 truncated discodermolide analogs.

\section{Synthesis of compound libraries}

The power of FMS has been further demonstrated in the preparation of a 560-member library of mappicine analogs (Scheme 6). ${ }^{10}$ A mixture of seven pyridines $\mathbf{M - 1}$ (7 different $\mathrm{R}^{1}$ groups paired with 7 different Rf) underwent iodo exchange followed by demethylation to give $\mathbf{M}-\mathbf{2}$. The mixture was then split into 8 portions and subjected to $N$-propargylations with 8 different bromides to give 8 mixtures of $\mathbf{M}-\mathbf{3}$. Each of the 8 mixtures of $\mathbf{M}-3$ was further split to 10 portions for radical annulation reaction with isonitriles. The resulting 80 mixtures of M-4 each containing seven tagged-products were demixed by fluorous HPLC and then detagged by HFpyridine to give a 560-member mappicine library (Figure 2). After each step, the reaction 
mixture could be analyzed by fluorous HPLC and the byproducts or unreacted starting materials were removed by normal-phase silica gel flash column chromatography. The synthesis of this 560-membered library is accomplished in 90 reactions (not including detag), while 630 steps are needed for a corresponding parallel synthesis. The overall separations required only 90 chromatography steps compared to 630 chromatography steps needed for the parallel synthesis.

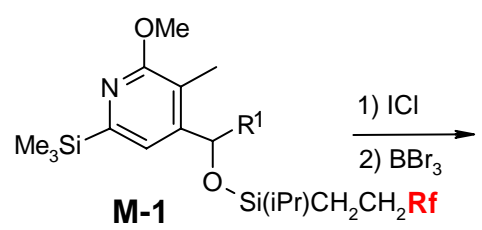

1 mixture of 7<smiles>[R]C(O[SiH3])c1cc(I)[nH]c(=O)c1C</smiles>

M-2

1 mixture of 7

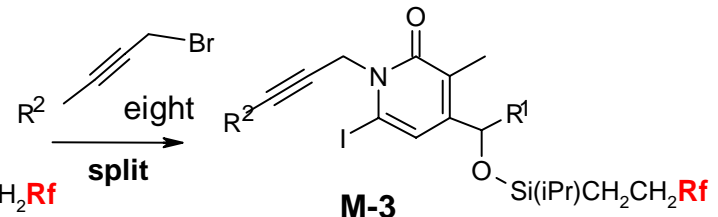

8 mixtures of 7<smiles>[R3]c1ccc(NC(C)C)cc1</smiles>

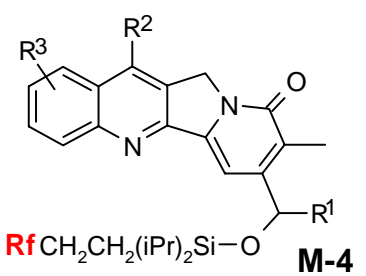
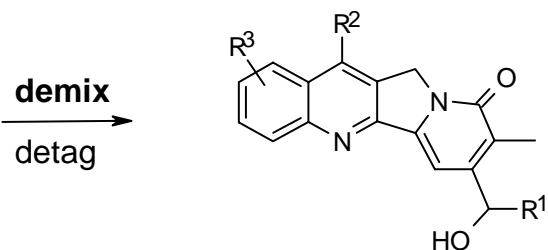

560 mappcine analogs

80 mixtures of 7

\begin{tabular}{ll|ll}
\hline \multicolumn{2}{c|}{$\mathrm{Rf}$} & \multicolumn{2}{c}{$\mathrm{R}^{1}$} \\
$\{1\} \mathrm{C}_{3} \mathrm{~F}_{7}$ & $\{5\} \mathrm{C}_{8} \mathrm{~F}_{17}$ & $\{1\} \mathrm{Me}$ & $\{5\} i-\mathrm{Pr}$ \\
$\{2\} \mathrm{C}_{4} \mathrm{~F}_{9}$ & $\{6\} \mathrm{C}_{9} \mathrm{~F}_{19}$ & $\{2\} \mathrm{Pr}$ & $\{6\} \mathrm{C}-\mathrm{C}_{6} \mathrm{H}_{11}$ \\
$\{3\} \mathrm{C}_{6} \mathrm{~F}_{13}$ & $\{7\} \mathrm{C}_{10} \mathrm{~F}_{21}$ & $\{3\} \mathrm{Et}$ & $\{7\} \mathrm{C}_{2} \mathrm{H}_{4}-c-\mathrm{C}_{6} \mathrm{H}_{11}$ \\
$\{4\} \mathrm{C}_{7} \mathrm{~F}_{15}$ & & $\{4\} \mathrm{S}-\mathrm{Bu}$ &
\end{tabular}

$\begin{array}{ll}\{1\} \mathrm{H} & \{5\} \mathrm{Pr} \\ \{2\} \mathrm{m}-\mathrm{MeOPh} & \{6\} \mathrm{Bu} \\ \{3\} \mathrm{Me} & \{7\} \mathrm{C}_{5} \mathrm{H}_{11} \\ \{4\} \mathrm{Et} & \{8\} \mathrm{Ph}\end{array}$

$\{1\} \mathrm{H}$

$\{2\} p-F$ $\mathrm{R}^{3}$ $\{3\} p-O M$ e $\{8\} o-F$ $\{4\} p-\mathrm{CF}_{3} \quad\{9\} p-\mathrm{Me}$ $\{5\} p$-Et $\quad\{10\} p$-SMe

Scheme 6. 7-Component FMS of a 560-member mappicine library. 

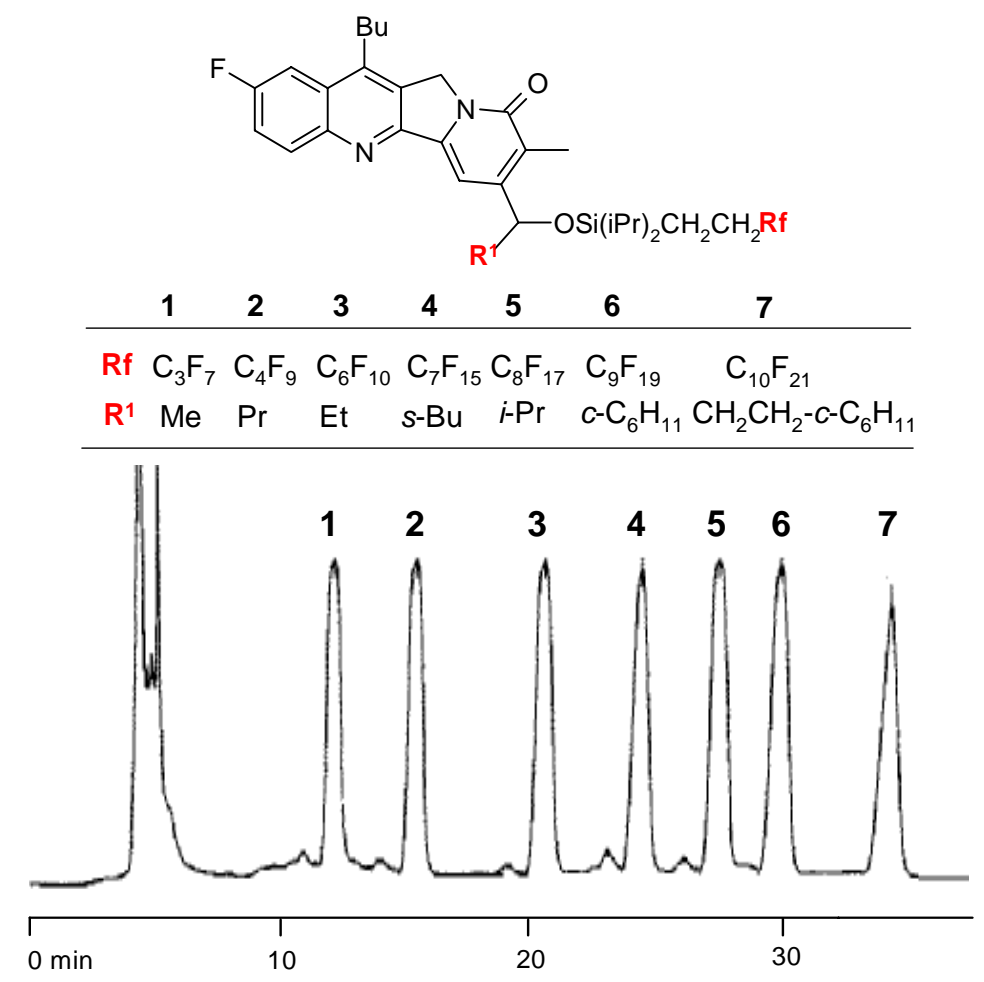

Fluorous HPLC column ( 20 x $250 \mathrm{~mm}, 5 \mu \mathrm{m}$ ), gradient 88\% MeOH-12\% $\mathrm{H}_{2} \mathrm{O}$ to $100 \% \mathrm{MeOH}$ in $28 \mathrm{~min}$, then to $100 \% \mathrm{THF}$ in $7 \mathrm{~min}$, flow rate $12 \mathrm{~mL} / \mathrm{min}$.

Figure 2. A typical HPLC demix of a 7-component mixture.

\section{Conclusions}

The fluorous tag-based HPLC has made possible the development of highly efficient solutionphase mixture synthesis. Compared to solid-phase synthesis, FMS has advantages of homogeneous reaction environment, easy analysis and purification of reaction intermediates, easy adoption of traditional solution-phase reaction conditions, does not require large excess of reagents for reaction completion, and good chemical and thermostability of fluorous tags. This new technology has been demonstrated for the synthesis of enantiomers, diastereomers, and compound libraries. There is no doubt it will play a more important role in organic, medicinal, and combinatorial chemistries.

\section{Acknowledgments}

I thank Professor Dennis Curran and his group for their pioneering and continuous work on FMS, my co-workers Dr. Zhiyong Luo and Ms. Christine Chen for their contributions to the 
mappicine project, and Dr. Sivaraman Dandapani for his helpful comments on this article. I also thank National Institutes of General Medical Sciences for Phase I and Phase II SBIR grants (1R43GM062717-01 and 2R44GM062717-02).

\section{References}

1. Recent reviews: (a) Curran, D. P. Angew. Chem., Int. Ed. 1998, 37, 1175. (b) Curran, D. P. In Stimulating Concepts in Chemistry; Stoddard, F.; Reinhoudt, D.; Shibasaki, M., Eds.; Wiley-VCH: New York, 2000; pp 25-37. (c) Yoshida, J.; Itami, K. Chem. Rev. 2002, 102, 3693. (d) Tzschucke, C. C.; Markert, C.; Bannwarth, W.; Roller, S.; Hebel, A. Angew. Chem. Int. Ed. 2002, 41, 3964. (e) Zhang, W. Tetrahedron 2003, 59, 4475. (f) Zhang, W. Chem. Rev. 2004, 104, 2531. (g) Gladysz, J. A.; Hovath, I.; Curran. D. Eds; The Handbook on Fluorous Chemistry, Wiley-VCH: 2004, in press.

2. (a) Curran, D. P. Synlett 2001, 1488. (b) Curran, D. P.; Oderaotoshi, Y. Tetrahedron 2001, 57, 5243.

3. For more information on FluoroFlash ${ }^{\mathrm{TM}}$ HPLC columns, log on to: www.fluorous.com.

4. Curran, D. P.; Luo, Z. J. Am. Chem. Soc. 1999, 121, 9069.

5. (a) Luo, Z.; Zhang, Q.; Oderaotoshi, Y.; Curran, D. P. Science 2001, 291, 1766. (b) Zhang, W. Chim. Oggi 2003, 21(3-4), 22.

6. Zhang, Q.; Rivkin, A.; Curran, D. P. J. Am. Chem. Soc. 2002, 124, 5774.

7. Curran, D. P.; Amatore, M.; Campbell, M.; Go, E.; Guthrie, D.; Luo, Z. J. Org. Chem. 2003, 68, 4643.

8. Zhang, Q.; Lu, H.; Richard, C.; Curran, D. P. J. Am. Chem. Soc. 2004, 126, 36.

9. Curran, D. P.; Furukawa, T. Org. Lett. 2002, 4, 2233.

10. Zhang, W.; Luo, Z.; Chen, C. H.-T.; Curran, D. P. J. Am. Chem. Soc. 2002, 124, 10443.

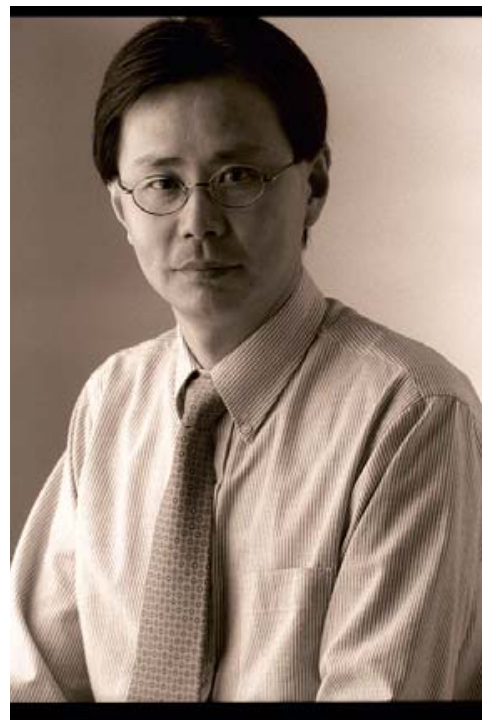

Biography: Dr. Wei Zhang received his B.S from Nanjing University and Ph.D in 1993 from the University of Pittsburgh under the supervision of late Professor Paul Dowd. After a two-year appointment at the same university as a Research Assistant Professor, he joined DuPont in 1995 and moved back to Pittsburgh in early 2001 to become one of the founding members at Fluorous Technologies, Inc. He is now the Director of Discovery Chemistry responsible for research and development of fluorous technologies for solution-phase synthesis and separations. Over the years Dr. Zhang has gained academic and industrial experience. His professional areas of interest include development of free radical reactions for ring-expansion and formation of heterocyclic systems, design and synthesis of drug-like small molecule libraries using the combinatorial technologies of fluorous synthesis, microwave-assisted organic reactions, and multicomponent reactions. He has published over 50 peer-reviewed papers including a recent article entitled "Fluorous synthesis of heterocyclic systems" in Chemical Reviews (2004, 104, 2531-2556). He has delivered many invited lectures on the topics of fluorous technologies and combinatorial chemistry. 